\title{
Preference for supernormal stimuli tends to override initially learned associations for conspicuous prey traits: implications from a laboratory study
}

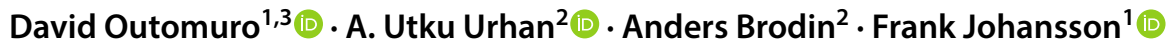

Received: 11 February 2020 / Accepted: 24 June 2020 / Published online: 2 July 2020

(c) The Author(s) 2020

\begin{abstract}
How predators select on conspicuous prey traits is not well understood. We used a laboratory setup to investigate the role of learning in predator choice of conspicuous visual traits. We used a generalist predator, the great tit, and coloured wings of males of two species of damselflies as prey. Wing pigmentation differs between the species in colour (green vs. blue) and size (large vs. small). Wing pigmentation is a sexually selected trait that experiences negative selection by avian predators. Inexperienced great tits showed no preference for the colour or the size of wing pigmentation. Great tits were then repeatedly exposed to rewarded wings with either large or small wing patch size. When these experienced birds were exposed to both wing patch sizes for the first time, they tended to prefer the wings with the large patch, irrespective of their previous experience. Our results suggest that the choice of the predator was based on an initial association of the trait to a reward followed by a preference for a supernormal stimulus, probably due to a larger sensory stimulation. We discuss the implications of our laboratory results in the light of previous estimates of damselfly predation risk under field conditions.
\end{abstract}

Keywords Calopteryx $\cdot$ Damselfly $\cdot$ Great tit $\cdot$ Passerine $\cdot$ Predation $\cdot$ Wing pigmentation

\section{Introduction}

Visual detection of prey can lead to more intense predation on certain visual prey traits, and predators that learn such traits can generalize to other traits (Kazemi et al. 2014). Generalization occurs if a novel stimulus resembles a known stimulus, evoking the same established behavioural response (e.g., predation) (Ghirlanda and Enquist 2003). Our knowledge of innate and learned predator preferences for prey traits has largely advanced in aposematic species, but is quite limited for other types of conspicuous traits (e.g., sexually selected traits) (Smith 1975; Svadova et al. 2009).

David Outomuro

outomuro.david@gmail.com

1 Department of Ecology and Genetics, Animal Ecology, Evolutionary Biology Centre, Uppsala University, Norbyvägen 18D, 75236 Uppsala, Sweden

2 Department of Biology, Lund University, Ecology Building, 22362 Lund, Sweden

3 Present Address: Department of Biological Sciences, University of Cincinnati, Rieveschl Hall, 45221 Cincinnati, OH, USA
For example, the visual signals that are intended to attract potential mates can be exploited by unintended receivers such as predators or parasitoids (e.g., Endler 1992; Zuk and Kolluru 1998). Understanding predator-mediated selection on sexually selected traits can help us to understand the interplay between natural and sexual selection shaping trait evolution (Kotiaho 2001; Ruxton et al. 2004).

In a laboratory setup, we investigated how predator preferences could influence selection of conspicuous prey traits. We were particularly interested in understanding the roles of learning and supernormal stimulus in predator choice. We used a generalist predator, the great tit (Parus major Linnaeus, 1758), and coloured wings of males of two species of Calopteryx, Leach 1815 damselflies as prey. Great tits are small passerines (body mass 17-18 g) that are innovative, capable of learning novel feeding behaviours and have a high level of self-control ability, which is considered to reflect general cognitive ability (Sasvári 1979; Gosler and Clement 2007; Cole et al. 2011; Isaksson et al. 2018). Wing pigmentation in Calopteryx damselflies differs between species in colour (blueish vs. greenish) and extent (central spot vs. most of the wing) (Fig. 1a) (Outomuro et al. 2017). This wing coloration has been estimated to not confer crypsis 
Fig. 1 a Wings of male $C$. splendens and $C$. virgo.

Pigmentation in Calopteryx wings is structural and therefore the observed colour will be affected, among other things, by the angle of incident light. This is probably the reason why, to the human eye, the colour of the wings is not clearly bluish or greenish in the figure. $\mathbf{b}$ Experimental arena with three petri dishes with wings. $\mathbf{c}$ and d Examples of wings cut down, mounted on the plastic and placed on top of a petri dish depicting small (c) and large (d) wing patches

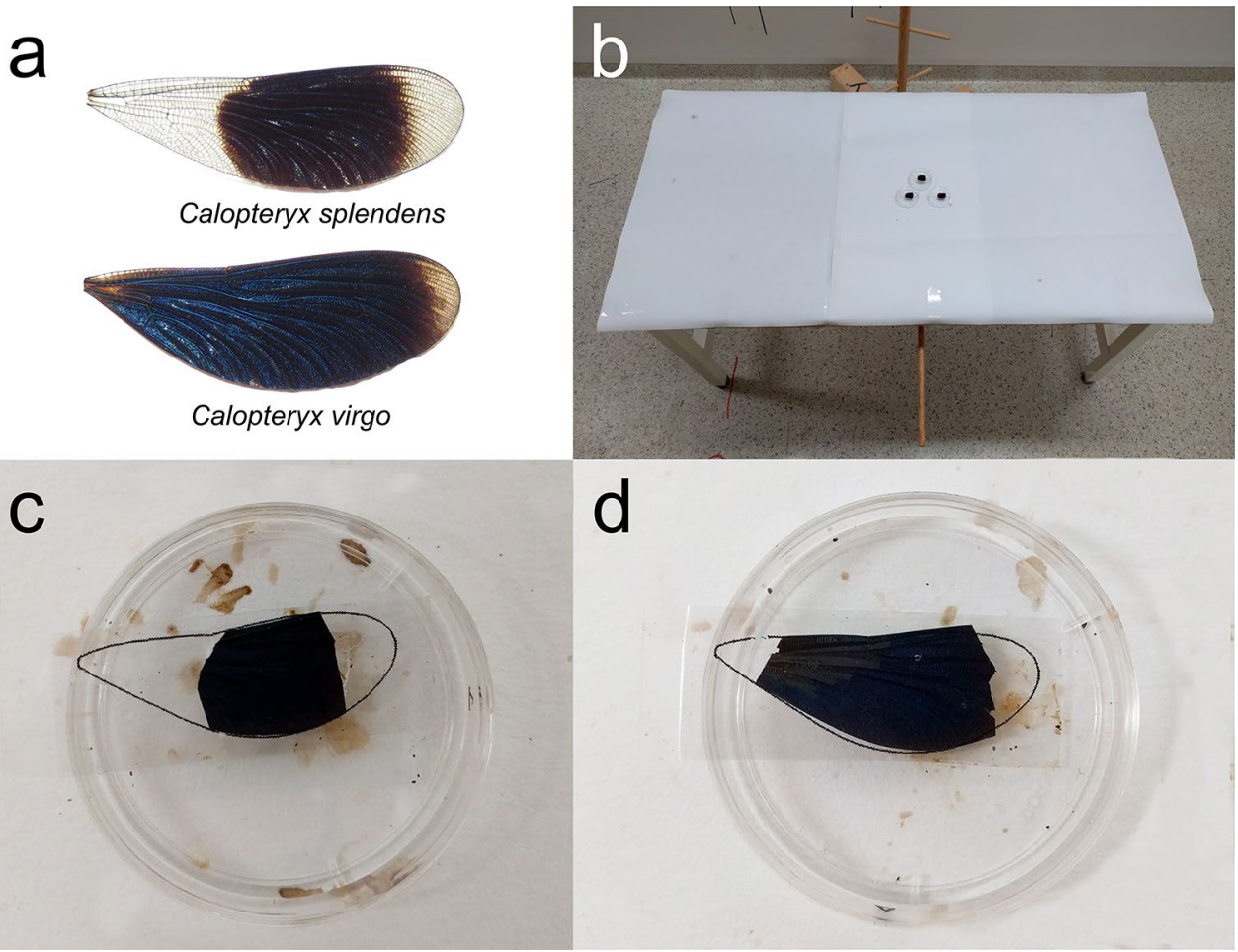

against the natural background, but instead being highly discriminable by the avian visual system (Outomuro et al. 2017). This wing trait is sexually selected, and subject to natural selection by avian predators (Svensson et al. 2004; Svensson and Friberg 2007; Outomuro and Johansson 2015). Our study system was inspired by natural populations of the two species of Calopteryx damselflies frequently predated by wagtails in Scandinavia (Svensson and Friberg 2007; Rantala et al. 2011). This study system represents one of the few well-documented examples of predator exploitation of conspicuous sexually selected traits in the wild (Svensson and Friberg 2007; Kuchta and Svensson 2014; Outomuro and Johansson 2015).

We aimed to understand the preference of wild-caught great tits for novel and learned prey stimuli using two sets of experiments: (1) we studied the preference of great tits for the colour and the size of the wing patch (i.e., novel stimuli); and (2) we repeatedly exposed great tits to either small or large wing patches positioned next to a food reward, and then tested whether this would create a consistent learned preference for the types of wing patches.

\section{Materials and methods}

\section{Ethical note}

The experiments involving the use of birds were performed under the regional ethical permit M 106-13 from the Malmö-Lund regional ethical permit board for animal experiments. No permits are required for collecting nonendangered insects in Sweden. Damselflies were euthanized by rapid freezing.

\section{Experimental individuals and laboratory setup}

We captured wild great tits during March 2016 and Feb-

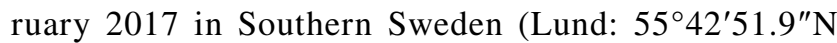
$13^{\circ} 12^{\prime} 26.1^{\prime \prime E}$; Höör: 5556'5.64"N, 1332'22.56"E). The birds were captured with a mist net, ringed and transferred to an individual cage in the laboratory within one hour. All birds were adults and both males and females were included in the experiment. One out of six birds were yearlings. In their cages, they had access to ad libitum water enriched with a commercial vitamin mixture for birds (Allvitamin speciellt för burfåglar, Imazo), ad libitum crushed nut mix that contained sunflower seeds, peanuts and hemp nuts, and ad libitum lard balls that contained animal fat and seeds. On the first day only, they also had access to three mealworms, because birds are stimulated by living prey and adapt more quickly to captivity. The temperature in the laboratory was set at $14{ }^{\circ} \mathrm{C}$. All birds were exposed to an artificial photoperiod mimicking outdoor conditions. The laboratory lights had a natural daylight spectrum, with a 1-h dawn/dusk dimming function. Each bird was kept in the laboratory for 3 to 7 days, depending on the experiment (see below).

A total of six birds were kept in the laboratory at the same time. After using those six birds in an experiment, they were 
released back in the wild at the same location where they were captured and a new group of six birds was captured and transferred to the laboratory. Each group of six birds was captured on the same day. The six cages, each measuring $60 \mathrm{~cm} \times 60 \mathrm{~cm} \times 40 \mathrm{~cm}$, were in pairs on three levels of shelves. At each level, the two cages were located next to each other, and each pair of birds had visual and auditory contact with each other. Birds were randomly assigned to each cage. In front of the shelves, there was a wooden wall from ceiling to floor. On this wooden wall, in front of each cage, were cage-sized doors which when opened made it possible for birds to see a full view of the experimental arena. Next to these doors, were smaller openings that connected to the cages by plastic tubes. In front of these small openings were remotely operated slide shutters that when opened allowed the bird to enter the lab where the experimental arena was located on a white table (Fig. 1b). The caged birds could not see the experimental arena during the experiments as the doors in front of the cages were closed. We observed the behaviour of each bird in the experimental arena through a one-way mirror. To make the bird return to its home cage, we turned off the light of the laboratory, making the gate to the home cage the only illuminated area of the laboratory. We let the bird return to its cage by itself. Our experimental setup aimed to reduce the disturbance and stress to the birds, which may be caused by handling before the experiment (Cockrem and Silverin 2002). The birds that consistently failed to inspect the experimental arena due to their stress levels were excluded from the experiment.

To study how the colour and size of wing pigmentation affect predation by birds, we used damselfly wings from males of Calopteryx virgo (Linnaeus, 1758) and Calopteryx splendens Harris, 1780 captured in 2015 near Uppsala, Sweden. C. virgo has most of the wing pigmented and shows a greenish coloration (peak around $455 \mathrm{~nm}$ ), whereas $C$. splendens has a central wing spot with more bluish coloration (peak around $430 \mathrm{~nm}$ ) (Fig. 1a) (Outomuro et al. 2017). Great tits include damselflies as part of their diet (Gosler and Clement 2007), although we note that we are not aware of any reports of great tit predation specifically on damselflies of the genus Calopteryx. To create the prey stimulus, the non-pigmented part of the wing was first cut out of the rest of the wing using a blade (see next section for rationale) and the pigmented part was glued to a transparent rectangular piece of plastic that was placed on top of a small Petri dish (Fig. 1c, d). The wing patches were 27-mm long for C. virgo and 14-mm long for C. splendens. These lengths were estimated from individuals collected from populations used in the experiments. If the Petri dish was to be a rewarding one, a portion of a mealworm was placed under the plastic with the wing. The birds had to flip or move the plastic with the wing to obtain the reward. The petri dishes were presented on the white table (Fig. 1b). We only used one wing in order to resemble the resting position of the damselflies (when perching, Calopteryx damselflies fold all four wings on top of each other).

\section{Experimental trials and data analysis}

\section{Experiment I: inexperienced birds}

The purpose of this experiment was to examine if wildcaught birds prefer a certain wing patch colour and/or size. Even though we can assume that the birds used were inexperienced to our experimental setup, we cannot assume that the birds have no previous experience to the stimuli presented (Calopteryx wings) or with beetle species that have green/blue metallic colorations. We will consider these limitations in the discussion section, in the context of the results obtained.

We captured two batches of six birds for this experiment (only six birds can be housed in the laboratory at a time), but two of the birds were excluded due to high levels of stress, leaving a total of ten birds in this part of the study. After spending one day in the cage, each bird was individually released into the laboratory for $1 \mathrm{~h}$ on the morning of day two. We had positioned three petri dishes with mealworms (but without wings) on the table, in order to attract attention to the experimental arena. The birds consumed the mealworms from the Petri dishes on the table during that hour. On day three we estimated preferences for wing patch types. We started the experiment by estimating preference for wing patch colour. The session was started by placing 12 petri dishes with rewards, alternating wing colour types (i.e., every second was a $C$. virgo or a $C$. splendens wing). The petri dishes were placed in two parallel lines along the length of the table. To avoid confounding effects due to the different wing patch size between species, we cut down wings of $C$. virgo to match the size of $C$. splendens, i.e., 14-mm long (Fig. 1c). We also cut out the transparent part of the wing of $C$. splendens to agree with the procedure done in $C$. virgo wings. We noted the wing that was first inspected and flipped to obtain the mealworm, i.e., the first choice of each bird. On day four, we estimated preference for wing patch size. We then again placed 12 petri dishes with rewards, this time alternating large and small wing patch sizes every two dishes. To avoid confounding effects of colour, we used only $C$. virgo wings, either with the whole wing patch, or cut down to match the size of $C$. splendens (Fig. 1c, d). We recorded the first choice of each bird. We then tested whether the birds had any preference for wing patch colour or size using separate $\chi^{2}$-tests. 


\section{Experiment II: experienced birds}

We first ran a preliminary experiment to test whether the birds can learn to distinguish both types of stimuli. We used four birds from experiment I, i.e., they had been exposed once to different wing patch size and colour, rewarded in all cases. We exposed the birds to eight training sessions in order to create a preferred response towards one type of wing patch size. On day one and day two, we trained each bird twice in the morning and twice in the afternoon, and we ran the experimental trial on day three. The training sessions consisted on placing six petri dishes on the table, three on the left half of the table and three on the right half of the table. In one side, the dishes had all large wing patches, and in the other side, all had small wing patches. As in the second part of experiment I, we only used wings of $C$. virgo to avoid possible confounding effects due to colour. Only one side was provided with rewards in the petri dishes, and we always rewarded the same type of wing patch for the same bird throughout the experiment (two birds trained for large, and two birds for small). The wing types were presented alternating the side of the table between consecutive trainings, to avoid spatial learning. During each training session, each bird was released one by one in the experimental room, and we let each bird inspect all the dishes. Once all the dishes were inspected, the bird was returned to the cage. Each training session thus only consisted of a few minutes, but it varied across individuals to provide enough time for the inspection of all petri dishes. The experimental trial consisted of three wings of each wing patch type, placed longitudinally and alternated along the centre of the table. Each of the six wings contained rewards. We recorded the first choice of each bird.

After the preliminary experiment, we ran a new experiment to test for preferences of wing patch size in new wildcaught birds that had been previously trained to recognize only one type of wing patch size as a rewarded stimulus (i.e., large or small wing patch), when exposed simultaneously to both patch size types. We used 24 new, wild-caught great tits. However, six birds were too stressed, and they were not included in the final results (giving a final sample size of 18 birds). The general methodology was similar to experiment 1. We left the birds in individual cages during day one. On day two, they were individually released into the lab for one hour, and petri dishes with mealworms were offered on the experimental arena. The four following days we exposed the birds to 12 training sessions. On days three and four, each bird was trained once in the morning and once in the afternoon. On days five and six, each bird was trained twice in the morning and twice in the afternoon. On day seven, the experimental test was run. In each training session, we presented three petri dishes with rewards in the centre of the table, with one of the two wing patch types (i.e., either a large or small wing patch size, all from C. virgo) (Fig. 1b). We allowed each bird to interact with the three petri dishes and consume the rewards. The bird was then immediately returned to the cage. For each bird, the wing patch type was kept the same during all training sessions, and the bird was never exposed to the alternative type during the training. Nine birds were trained for small wing patches, and nine birds for large wing patches. For the experimental test, we placed six petri dishes with alternating wing types along the length of the centre of the table. All petri dishes contained rewards. We recorded the first choice of each bird. The results were analysed using a logistic regression model using the function glm in R (R Core Team 2019), with family binomial. Choice was entered as a binomial response variable, i.e., correct vs. incorrect choice, depending on the training received by the test subject. Experienced training was entered as a fixed effect (large vs. small wing patch size).

\section{Data availability}

All data generated during this study are included in this published article.

\section{Results}

\section{Experiment I: inexperienced birds}

Inexperienced wild-caught great tits did not show any preference for the colour (four birds chose $C$. virgo and six birds chose $C$. splendens, $P=0.527$ ) or the size of the wing patch (six birds chose large wing patch and four birds chose small wing patch, $P=0.527$ ).

\section{Experiment II: experienced birds}

The preliminary experiment showed that both birds trained for large wing patch (L1 and L2) selected large in the first place, and out of the two birds trained for small wing patch (S1 and S2), only S2 selected small in the first place. Due to the small sample size, these results are not satisfactorily enough for stating learning. However, we also inspected the first choice during the seven training sessions (the first session cannot be counted as learning). The birds chose correctly:incorrectly as follows, L1 6:1 (i.e., bird L1, trained for large wing patch, chose large wing patch correctly six times and incorrectly one time), L2 5:2, S1 6:1, and S2 5:0 (in two training episodes $\mathrm{S} 2$ did not make any choices). This accounts for 22 correct choices versus 4 times incorrectly. We think these results present clear evidence for the ability to learn and being able to distinguish between large and small wing patches. 
After this preliminary experiment, we exposed new birds to 12 training sessions with a rewarded type of wing patch size. Out of nine birds trained for small patch size, only three selected the small type in the experimental trial, and out of nine birds trained for large size, seven selected the large type in the experimental trial (Fig. 2). Therefore, we found that once the birds learned to associate a type of wing patch size to a reward, the birds tended to preferably choose the large wing patch as the first choice, irrespective of previous training $(\mathrm{z}=1.820, P=0.069$, odds ratio $=7.0$, odds ratio $95 \%$ CI 0.975-72.556) (Fig. 2). We note that this result was not driven exclusively by the birds trained for a large wing patch.

\section{Discussion}

Our experimental results suggest that great tits first may need to associate the stimulus to the reward, after which there may occur a preference for larger prey traits (see also Krebs et al. 1977; Houston et al. 1980). Indeed, training on one type of wing patch size did not lead to clear preferences that could overrule the effect of a supernormal stimulus (Tinbergen 1951). If this is the case, greater sensory stimulation is not an active mechanism employed before the concept or categorization is created.

Our result suggests that birds may have a preference towards the larger wing patch as a first choice, i.e., more conspicuous ornaments are imposing a higher risk of predation. However, we note that this result was only marginally significant $(P=0.069)$, probably due to a small sample size. A preference for a larger signal is present in multiple ethological contexts (Ryan and Keddy-Hector 1992; Rosenthal et al. 2001), including visual predation by insectivorous birds
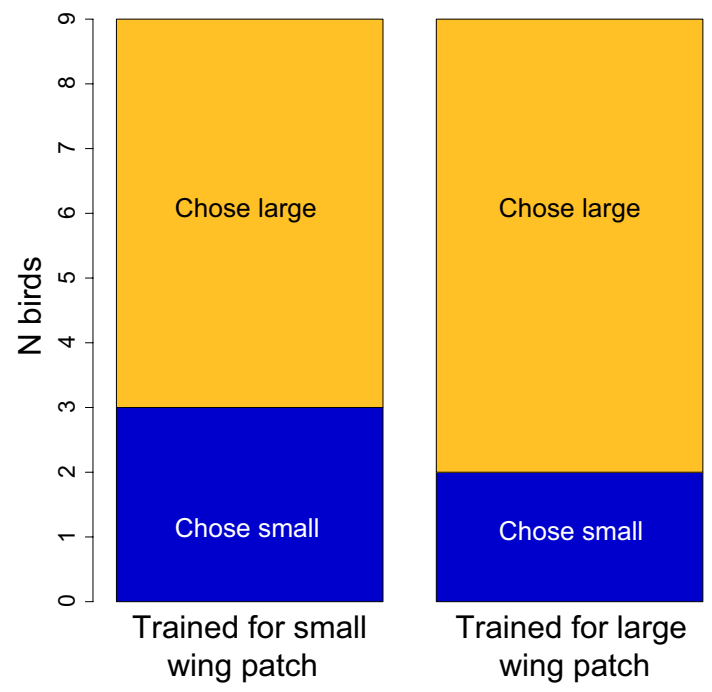

Fig. 2 First choices made by birds trained to prefer large or small wing patches
(Curio 1976; great tits: Naef-Daenzer et al. 2000; wagtails: Bures 1995), and extends to other sensory cues (e.g., acoustic: Lindström et al. 2006). Generalization alone may explain why some birds trained for large wing patch preferred the small wing patch and vice versa, but not the overall tendency to prefer large wing patches. The mechanism behind this tendency might be biased generalization (reviewed in Ghirlanda and Enquist 2003; ten Cate and Rowe 2007). If the novel stimulus elicits a stronger response than the familiar one (i.e., large wing patches are preferred over small wing patches), this mechanism is known as response bias (Ghirlanda and Enquist 2003). Generalization and the amount of bias to a novel stimulus will depend on several factors such as discriminability of the stimuli, the stimulation of the receptors in the receiver, how the stimuli are processed in the nervous system, and how the receiver responds to novel stimuli based on genetically inherited and learned responses (Ghirlanda and Enquist 2003; ten Cate and Rowe 2007). The birds tended to prefer large wing patches, suggesting that this phenomenon might be an example of biased generalization towards a supernormal stimulus. Birds might also be generalizing their experience from the wild, so that larger prey size is associated with a larger food reward (Naef-Daenzer et al. 2000). However, since the birds were not subjected to previous discriminatory training in the laboratory (Ghirlanda and Enquist 2003; Lynn et al. 2005), our conclusion on biased generalization must be taken with caution. Training birds with positive and negative stimuli (e.g., rewarded small wing patch and unrewarded wings without patches) before being presented with the supernormal stimulus (i.e., large wing patch) would help to understand the predatory response curve of the bird and whether the response is truly biased.

Our results are based on the assumption that the birds can learn to distinguish between small and large wing patches. Our preliminary part of experiment II showed that three out of four birds chose the learned wing patch in the first place during the experimental test. This result is weak due to the small sample size. By inspecting the first choice during each of the training trials, we found that birds chose 22 times correctly, 4 times incorrectly and there were 2 times where the birds did not make any choices. We believe this second result strongly suggest the ability of these birds to learn and distinguish the two wing patches. This is not surprising given that great tits have advanced cognitive abilities (Isaksson et al. 2018).

We note that we did not know the previous history of each experimental subject, and whether they had any experience with Calopteryx wings in the wild. We performed our experiments in February and March, while adult damselflies are present in the study area about 2 months: June and July. Birds could also have experience with other similarly coloured insects such as beetles. However, without appropriate reflectance measurements, it is not possible to ascertain if 
the birds perceive beetle colorations as similar to Calopteryx wings. Despite these uncertainties, our results suggest that we were able to distinguish responses from inexperienced birds and trained birds: birds did not show any populationlevel preference for the colour or the size of the wing patch when first exposed to the experimental stimuli, but once they could associate our experimental stimuli as rewarded, they tended to show a preference for a supernormal stimulus.

\section{How do our results translate to natural populations?}

Calopteryx damselflies are actively predated by wagtails in Scandinavia (Svensson and Friberg 2007; Rantala et al. 2011). In sympatric populations of $C$. splendens and $C$. virgo, predation risk in males is three to four times higher in the species with the large wing patch $(C$. virgo) than it is in the species with the small wing patch (C. splendens) (Svensson and Friberg 2007; Outomuro et al. 2017). This preference occurs even when the proportion of $C$. splendens exceeds that of $C$. virgo by more than 60 times (Outomuro et al. 2017). Our experimental results on great tits support what it has been observed in wagtails in the field. We thus predict that wagtails first create a concept or categorization of the damselfly as a prey item, followed by a generalization biased towards the damselfly species with the largest wing coloration. Indeed, receiver biases can shape the evolution of signal traits (e.g., pollinators on flower colours: Lynn et al. 2005; partners on sexual ornaments: Ten Cate and Rowe 2007; predators on warning signals: Gamberale-Stille et al. 2018).

One limitation of our experimental setup is that our experiments involve only stationary prey items. We note, however, that wagtails prey on flying prey at a lower proportion than predation on the ground or from vegetation (Davies 1977). Both great tits and wagtails show certain similarities. First, great tits have the ability to learn to discriminate between rewarded and unrewarded colour stimuli and change their preference when the rewarded and unrewarded stimuli are switched, which can indicate flexibility in foraging behaviour (Amy et al. 2012; Morand-Ferron et al. 2015). There is not much known about wagtail learning abilities and prey selection (but see Davies 1977), but we know that they can shift prey preferences and that they select aboveaverage sized prey (Bures 1995). Second, neither great tits nor wagtails are highly specialized in feeding on Calopteryx damselflies. We did not want to use wagtails in our experiments because they are migratory, and we do not consider it ethical to use them during their breeding season. Great tits are non-migratory, and we tested them only during the non-breeding season.

There are other potential explanations for why C. virgo experiences a higher predation risk compared to C. splendens in sympatric populations. First, $C$. virgo males are slightly larger than $C$. splendens, although the small size difference (about half a millimetre, see Tynkkynen et al. 2004 ) is probably not the major driver of predator choice. Second, males are territorial and usually $C$. virgo is dominant over $C$. splendens (Tynkkynen et al. 2004). Since male territories are usually located at more exposed areas in the riverine habitat, this might lead to larger exposure to predation risk in $C$. virgo compared to $C$. splendens (Toivanen et al. 2009). However, since predation is always higher on $C$. virgo independent of population density, these two potential explanations for a higher predation on $C$. virgo are probably of minor importance compared to our proposed hypothesis of biased generalization towards a large wing patch.

\section{Concluding remarks}

Our experiments offer insights on the potential cognitive processes underlying visual predator selection of sexually selected traits of prey. A preference for supernormal stimulus may impose a higher predation cost for prey that carries more conspicuous, similar traits. Moreover, our results also suggest that birds may disproportionally predate on certain prey types, which may have implications in the dynamics of sympatric populations of closely related prey or mimics.

Acknowledgements Open access funding provided by Uppsala University. We are very grateful to Erik I. Svensson for his feedback on earlier versions of this manuscript. DO held a postdoctoral stipend supported by Olle Engkvist Byggmästare. DO was also supported by travel funds by the Foundation of Zoological Research. AUU was supported by a grant from the Royal Physiographic Society of Lund. $\mathrm{AB}$ was supported by a Grant from Carl Tryggers foundation. FJ was supported by Nycanders Foundation at Uppsala University and the Swedish Research Council.

Open Access This article is licensed under a Creative Commons Attribution 4.0 International License, which permits use, sharing, adaptation, distribution and reproduction in any medium or format, as long as you give appropriate credit to the original author(s) and the source, provide a link to the Creative Commons licence, and indicate if changes were made. The images or other third party material in this article are included in the article's Creative Commons licence, unless indicated otherwise in a credit line to the material. If material is not included in the article's Creative Commons licence and your intended use is not permitted by statutory regulation or exceeds the permitted use, you will need to obtain permission directly from the copyright holder. To view a copy of this licence, visit http://creativecommons.org/licenses/by/4.0/.

\section{References}

Amy M, van Oers K, Naguib M (2012) Worms under cover: relationships between performance in learning tasks and personality in great tits (Parus major). Anim Cogn 15:763-770

Bures S (1995) Responses of grey wagtail Motacilla cinerea to changing prey availability during the nesting period. J Avian Biol $26: 325-329$ 
Cockrem JF, Silverin B (2002) Variation within and between birds in corticosterone responses of great tits (Parus major). Gen Comp Endocr 125:197-206

Cole EF, Cram DL, Quinn JL (2011) Individual variation in spontaneous problem-solving performance among wild great tits. Anim Behav 81:491-498

Core Team R (2019) R: a language and environment for statistical computing. R Foundation for Statistical Computing, Vienna

Curio E (1976) The ethology of predation. Springer, Berlin

Davies NB (1977) Prey selection and social-behavior in wagtails (AvesMotacillidae). J Anim Ecol 46:37-57

Endler JA (1992) Signals, signal conditions, and the direction of evolution. Am Nat 139:S125-S153

Gamberale-Stille G, Kazemi B, Balogh A, Leimar O (2018) Biased generalization of salient traits drives the evolution of warning signals. Proc R Soc B 285:20180283

Ghirlanda S, Enquist M (2003) A century of generalization. Anim Behav 66:15-36

Gosler A, Clement P (2007) Family Paridae (tits and chickadees). In: del Hoyo J, Elliot A, Christie D (eds) Handbook of the birds of the world. Lynx edicions, Barcelona, pp 662-750

Houston AI, Krebs JR, Erichsen JT (1980) Optimal prey choice and discrimination time in the great tit (Parus major L.). Behav Ecol Sociobiol 6:169-175

Isaksson E, Urhan AU, Brodin A (2018) High level of self-control ability in a small passerine bird. Behav Ecol Sociobiol 72:118

Kazemi B, Gamberale-Stille G, Tullberg BS, Leimar O (2014) Stimulus salience as an explanation for imperfect mimicry. Curr Biol 24:965-969

Kotiaho JS (2001) Costs of sexual traits: a mismatch between theoretical considerations and empirical evidence. Biol Rev 76:365-376

Krebs JR, Erichsen JT, Webber MI (1977) Optimal prey selection in the great tit. Anim Behav 25:30-38

Kuchta SR, Svensson EI (2014) Predator-mediated natural selection on the wings of the damselfly Calopteryx splendens: differences in selection among trait types. Am Nat 184:91-109

Lindström L, Ahtiainen JJ, Mappes J, Kotiaho JS, Lyytinen A, Alatalo RV (2006) Negatively condition dependent predation cost of a positively condition dependent sexual signalling. J Evol Biol 19:649-656

Lynn SK, Cnaani J, Papaj DR (2005) Peak shift discrimination learning as a mechanism of signal evolution. Evolution 59:1300-1305

Morand-Ferron J, Hamblin S, Cole EF, Aplin LM, Quinn JL (2015) Taking the operant paradigm into the field: associative learning in wild great tits. PLoS ONE 10:e0133821. https://doi.org/10.1371/ journal.pone. 0133821

Naef-Daenzer L, Naef-Daenzer B, Nager RG (2000) Prey selection and foraging performance of breeding great tits Parus major in relation to food availability. J Avian Biol 31:206-214
Outomuro D, Johansson F (2015) Bird predation selects for wing shape and coloration in a damselfly. J Evol Biol 28:791-799

Outomuro D, Söderquist L, Johansson F, Ödeen A, Nordström K (2017) The price of looking sexy: visual ecology of a three-level predator-prey system. Funct Ecol 31:707-718

Rantala MJ, Honkavaara J, Dunn DW, Suhonen J (2011) Predation selects for increased immune function in male damselflies, Calopteryx splendens. Proc B 278:1231-1238

Rosenthal GG, Martinez TYF, de Leon FJG, Ryan MJ (2001) Shared preferences by predators and females for male ornaments in swordtails. Am Nat 158:146-154

Ruxton GD, Sherrat TN, Speed MP (2004) Avoiding attack: the evolutionary ecology of crypsis, warning signals and mimicry. Oxford University Press, New York

Ryan MJ, Keddy-Hector A (1992) Directional patterns of female mate choice and the role of sensory biases. Am Nat 139:S4-S35

Sasvári L (1979) Observational learning in great, blue and marsh tits. Anim Behav 27:767-771

Smith SM (1975) Innate recognition of coral snake pattern by a possible avian predator. Science 187:759-760

Svadova K, Exnerova A, Stys P, Landova E, Valenta J, Fucikova A, Socha R (2009) Role of different colours of aposematic insects in learning, memory and generalization of naive bird predators. Anim Behav 77:327-336

Svensson EI, Friberg M (2007) Selective predation on wing morphology in sympatric damselflies. Am Nat 170:101-112

Svensson E, Kristoffersen L, Oskarsson K, Bensch S (2004) Molecular population divergence and sexual selection on morphology in the banded demoiselle (Calopteryx splendens). Heredity 93:423-433

ten Cate C, Rowe C (2007) Biases in signal evolution: learning makes a difference. Trends Ecol Evol 22:7

Tinbergen N (1951) The Study of Instinct. Oxford University Press, London

Toivanen T, Rantala MJ, Suhonen J (2009) Influence of alternative mating tactics on predation risk in the damselfly Calopteryx virgo. Can J Zool 87:684-688

Tynkkynen K, Rantala MJ, Suhonen J (2004) Interspecific aggression and character displacement in the damselfly Calopteryx splendens. J Evol Biol 17:759-767

Zuk M, Kolluru GR (1998) Exploitation of sexual signals by predators and parasitoids. Q Rev Biol 73:415-438

Publisher's Note Springer Nature remains neutral with regard to jurisdictional claims in published maps and institutional affiliations. 